
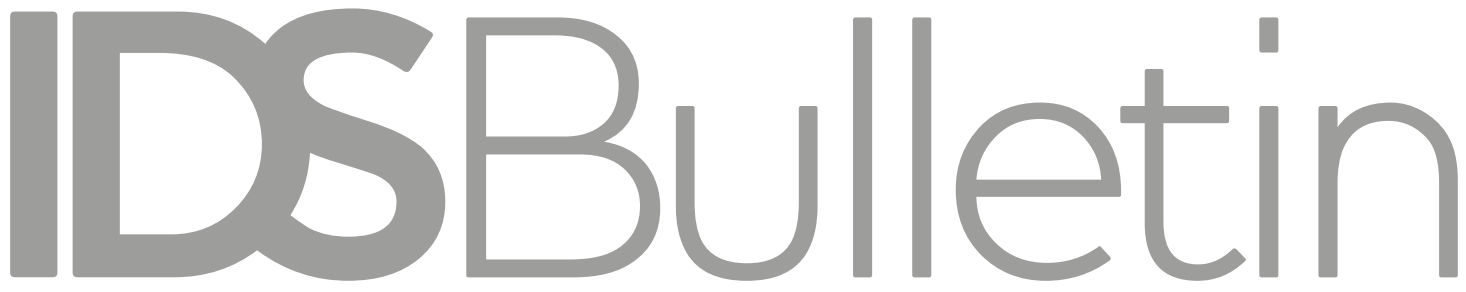

Transforming

Development Knouledge

Volume 48 Number 2 | March 2017

\title{
INTERROGATING DECENTRALISATION IN AFRICA
}

Editors Shandana Khan Mohmand and Miguel Loureiro

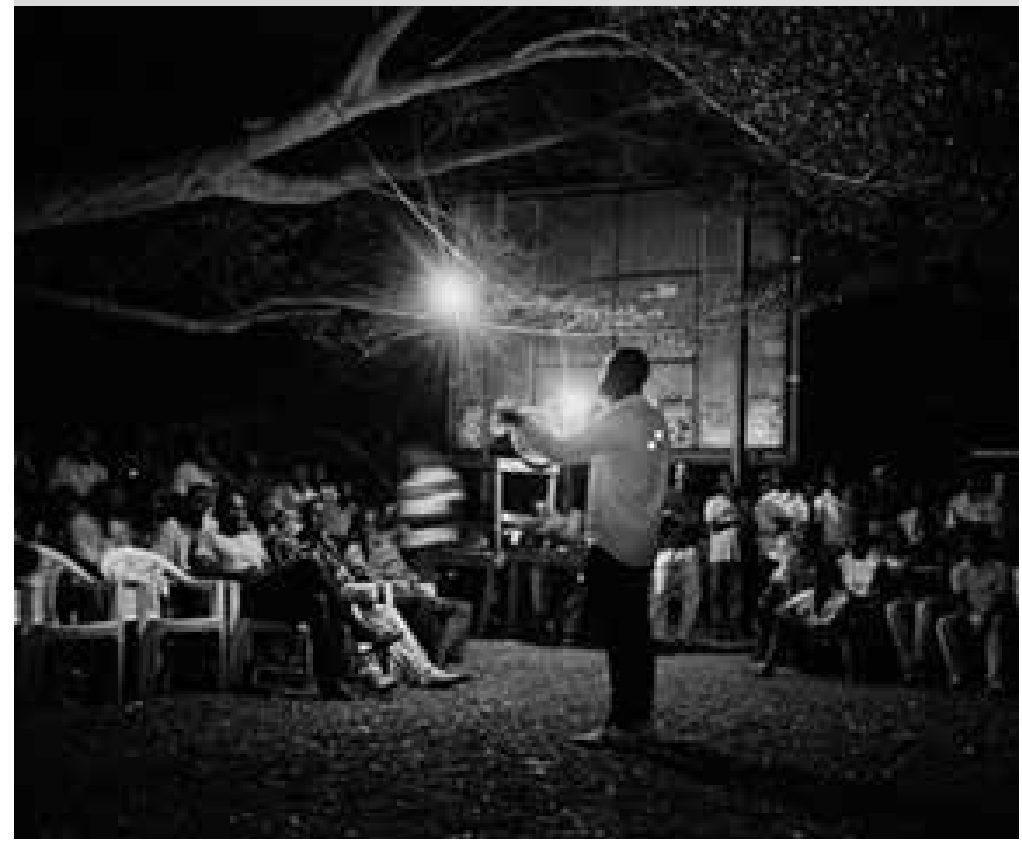


Notes on Contributors

Foreword

Diana Conyers

\section{Introduction: Interrogating Decentralisation in Africa}

Shandana Khan Mohmand and Miguel Loureiro

Democratic Decentralisation, Clientelism and Local Taxation in Ghana

Richard C. Crook

Is Election a Disadvantage? Nigerian Local Councils and Security Provision

Ayobami Ojebode, Ike Ernest Onyishi and Fatai A. Aremu

Formal and Informal Actors in Addis Ababa's Solid Waste Management System Kassa Teshager Alemu

Staff Quality and Service Delivery: Evaluating Two Ghanaian District Assemblies Daniel Doh

Improving Access to Maternal Health Care through Devolution in Western Kenya Susan Kilonzo, Eunice Kamaara and Kitche Magak

Local Governments and Primary Education in Uganda

Emilly Comfort Maractho

Glossary 


\title{
Introduction: Interrogating Decentralisation in Africa
}

\author{
Shandana Khan Mohmand and Miguel Loureiro
}

\begin{abstract}
Decentralisation is a major policy item across many emerging African democracies. However, repeated waves of local government reforms have had little impact on the region's continuing problems with governance, and the decentralisation agenda remains incomplete. Yet, within this larger story there are smaller stories, of how different regions and different actors experience differential outcomes in the decentralisation process. Such stories have not been told in enough detail in the overall narrative on Africa's decentralisation efforts. This IDS Bulletin is an attempt to get at these micro, comparative stories by accumulating evidence on how decentralisation works differently in a series of countries, and the factors that are responsible for differential outcomes. Together, the six articles of this issue interrogate the extent to which decentralisation has affected change at the local level and identify the factors that may allow decentralisation efforts to have greater impact through future reforms.
\end{abstract}

Keywords: decentralisation, Africa, Ibrahim Index of African Governance, comparative studies, mixed methods.

\section{The state of governance in Africa}

In many parts of the world, increasing dissatisfaction with conventional representative systems of democracy has led to the emergence of various strategies to 'deepen democracy' by improving the quantity and quality of participation, and to deliver services that better meet the expectations of citizens. Decentralisation reforms have been a central and popular strategy within these efforts. In theory, the decentralisation of government to a more local level, where state officials can engage with citizens more directly and regularly, is meant to create more participatory and deliberative spaces for decision-making, and lead to more effective and efficient service delivery and better policies. There is certainly literature that supports this perspective (Crook and Manor 1998; Heller 2001; Ribot 2002a; Wunsch and Oluwu 2003; Bardhan and Mookherjee 2006a, 2006b; Crawford and Hartmann 2008; Faguet 2012, 2014; Smoke 2015). At the same time, there is also empirical evidence, including from these same authors, that suggests that we may need to be more cautious about decentralisation and its impact. Quite 
Vol. 48 No. 2 March 2017: 'Interrogating Decentralisation in Africa'

Figure 1 Ibrahim Index of African Governance 2016: ranking of the five country cases

\begin{tabular}{|c|c|c|c|c|c|}
\hline & \multirow{2}{*}{ Overall governance } & Safety and rule of law & $\begin{array}{l}\text { Participation and } \\
\text { human rights }\end{array}$ & $\begin{array}{l}\text { Sustainable economic } \\
\text { opportunities }\end{array}$ & Human development \\
\hline & & $\begin{array}{l}\text { Selected indicator: } \\
\text { personal safety }\end{array}$ & $\begin{array}{l}\text { Selected indicators: } \\
\text { participation; rights }\end{array}$ & $\begin{array}{l}\text { Selected indicator: } \\
\text { public management }\end{array}$ & $\begin{array}{l}\text { Selected indicators: } \\
\text { health; education }\end{array}$ \\
\hline \multicolumn{6}{|l|}{1} \\
\hline \multicolumn{6}{|l|}{2} \\
\hline \multicolumn{6}{|l|}{3} \\
\hline 4 & & & Ghana & & \\
\hline \multicolumn{6}{|l|}{5} \\
\hline 6 & & Ghana & & & \\
\hline 7 & Ghana & & & & \\
\hline \multicolumn{6}{|l|}{8} \\
\hline \multicolumn{6}{|l|}{9} \\
\hline \multicolumn{6}{|l|}{10} \\
\hline 11 & & & & Kenya & Ghana \\
\hline 12 & Kenya & & & & Kenya \\
\hline \multicolumn{6}{|l|}{13} \\
\hline 14 & & & & Uganda & \\
\hline 15 & & & & Ghana & \\
\hline \multicolumn{6}{|l|}{16} \\
\hline 17 & & & Kenya & & \\
\hline 18 & & & & & Uganda \\
\hline 19 & Uganda & & Uganda & & \\
\hline \multicolumn{6}{|l|}{20} \\
\hline \multicolumn{6}{|l|}{21} \\
\hline 22 & & Uganda & & & \\
\hline 23 & & & & Ethiopia & Ethiopia \\
\hline \multicolumn{6}{|l|}{24} \\
\hline 25 & & Kenya & & & \\
\hline 26 & & Ethiopia & Nigeria & & AFRICAN AVERAGE \\
\hline \multicolumn{6}{|l|}{27} \\
\hline \multicolumn{6}{|c|}{28 AFRICAN AVERAGE } \\
\hline \multicolumn{6}{|l|}{29} \\
\hline 30 & & & AFRICAN AVERAGE & AFRICAN AVERAGE & \\
\hline 31 & Ethiopia & & & & \\
\hline \multicolumn{6}{|l|}{32} \\
\hline \multicolumn{6}{|l|}{33} \\
\hline 34 & & & & Nigeria & \\
\hline 35 & & AFRICAN AVERAGE & & & \\
\hline 36 & Nigeria & & & & \\
\hline \multicolumn{6}{|l|}{37} \\
\hline 38 & & & & & Nigeria \\
\hline 39 & & & Ethiopia & & \\
\hline \multicolumn{6}{|l|}{40} \\
\hline \multicolumn{6}{|l|}{41} \\
\hline \multicolumn{6}{|l|}{42} \\
\hline 43 & & & & & \\
\hline 44 & & Nigeria & & & \\
\hline$\ldots$ & & & & & \\
\hline 54 & & & & & \\
\hline
\end{tabular}

Source Mo Ibrahim Foundation (2016a). 
often, discussions of decentralisation provide useful 'ideal types' of government - that lie closer to people, have budgets that more closely match local needs, and reflect greater citizen voice in decision-making on service provision - but which are quite difficult to realise in practice. Most often we find that the decentralisation agenda in emerging democracies remains incomplete (Treisman 2007; Faguet 2012; Bratton 2012; Joshi and Schultze-Kraft 2014).

Decentralisation has been a major policy agenda item across many African countries over the last few decades (Conyers 2007), and efforts to strengthen local governments have been aimed at dealing with the region's continuing problems with governance. However, after repeated waves of decentralisation - including quite recent reforms to strengthen and rewire the system in Ghana, Nigeria, Kenya, Uganda and Ethiopia, the five countries studied in detail in this IDS Bulletin - many of these problems remain. The Ibrahim Index of African Governance (IIAG) 2016 provides a comparative sense of these issues (Mo Ibrahim Foundation 2016a).

The IIAG shows some improvement in overall governance performance across the continent (the latest edition of the IIAG provides not only the annual scores and ranks for the 54 countries of Africa, but also trends over a decade). Of the five countries studied in this issue, Ethiopia and Kenya have shown encouraging improvement -7 and 5.1 per cent improvement, respectively, in the overall governance score assigned to them by the IIAG over a ten-year period from 2006 to 2015. Uganda and Nigeria have registered slight improvements with 3.4 per cent and 2.5 per cent respectively, and Ghana's score has decreased by 2.1 per cent over the last decade. In terms of the 2016 IIAG ranking, these countries cover a full spectrum of African cases. Ghana is part of the top ten African countries in terms of overall governance, ranked 7th despite its recent decreases. Kenya and Uganda lie above the African average, ranked 12th and 19th respectively, while Ethiopia and Nigeria lie below the average, at 31 st and 36 th of a total of 54 countries in the IIAG.

Figure 1 helps nuance these comparisons by providing a disaggregated ranking of each of these countries across a few key governance indicators, vis-à-vis the African average in 2016. This reveals that despite Ghana's impressive ranking overall, sub-indicators related to public management have registered a decrease in scores over the last decade. Some of these sub-indicators include effectiveness of public administration, budget management, ratio of revenue to expenditure, fiscal policy, and revenue mobilisation. In other words, Ghana is doing well vis-à-vis other African countries on governance, but it has not yet solved its problems in terms of public administration and fiscal management.

Of the other two countries that lie above the African average, Kenya has registered a real improvement in health outcomes between 2006 and 2015. This seems to be accompanied by a slight improvement also in the health sub-indicator that measures public satisfaction with 
how the government handles basic health services. Uganda though, appears to be an interesting puzzle. While many education indicators have improved over the past decade, primary school completion figures have remained stagnant and the score for 'education provision', which measures public satisfaction with how government handles educational needs, has decreased. So while inputs into service delivery may be improving - an increase in school enrolment, of teachers in primary schools, in funding, and in the involvement of more actors from the private sector - neither outcomes of this delivery nor satisfaction with government services are registering commensurate increases.

For the two countries that lie below the regional average in terms of overall scores, we notice in Figure 1 that Ethiopia ranks above the African average in three out of the four categories - safety and rule of law, sustainable economic opportunity, and human development - but lags in participation and human rights on measures such as 'political participation', 'civil society participation', and various freedoms. Nigeria's problems are of a different variety. Its major issues seem to be safety and rule of law, on which it ranks 44th out of 54 countries. It has seen some improvements, mainly in police services that have contributed to stronger scores on 'personal safety', but this has not led to improvements in terms of how safe people actually feel. In fact, there has been a decrease of public perception of neighbourhood safety in particular.

What is the significance of all this information? For instance, Ghana has one of the strongest governance systems in Africa but its bureaucratic processes seem to be lagging. Nigeria has one of the weakest systems but it has registered improvements over the last decade on some important indicators, including on rule of law and safety. What types of conclusions do we draw from such findings?

The problem with most composite measures, as with studies that focus on macro narratives and broad conclusions, is that they often conceal and conflate more than they reveal. A focus on decentralisation is an important way of giving a more realistic sense of how the governance reform agenda is working out at the grass roots. The decentralisation reforms that were instituted to deal with many of these governance problems may have few big stories to tell of transformative local governance, but there may be smaller stories - either of positive outcomes, or at least of how different parts of each country and different actors experience differential outcomes in the decentralisation process. Such smaller, more micro and comparative stories have not been told in enough detail in the overall narrative on Africa's decentralisation efforts.

This IDS Bulletin is an attempt to get at these micro, comparative stories by accumulating evidence on how decentralisation works differently within each country, and the factors that are responsible for differential outcomes. Decentralisation reforms in their most recent form in Africa have had three main aims: 'improved service delivery, democracy and participation, and a reduction in central government 
expenditure' (Conyers 2007). The studies in this IDS Bulletin deal with all three of these aims - the articles on Kenya, Uganda and Ghana look at issues of service delivery at the local level; those on Ethiopia and Nigeria raise questions about local democracy and participation by formal and informal actors; and the article on Ghana by Crook looks at issues of local revenue mobilisation. In doing so, each article considers in particular the country-specific areas highlighted in the IIAG 2016 previously mentioned - public administration in Ghana, security provision in Nigeria, participatory local governance in Ethiopia, education provision in Uganda and maternal health care in Kenya.

Together, the six articles of this issue interrogate the extent to which decentralisation has affected change at the local level - in terms of democratisation, participation and service delivery - and identify the factors that may allow decentralisation efforts to have greater impact through future reforms.

\section{Contributing to the narrative on decentralisation in Africa}

What are the smaller stories hidden within the larger trends highlighted by the IIAG 2016 on governance in Africa, and to what extent has decentralisation managed to affect change in these areas? More importantly, what are the factors that keep local government reforms from achieving more complete outcomes? These are the main questions that this IDS Bulletin asks. The articles in this collection focus on providing more nuanced and grounded explanations for the impact of decentralisation at the local level in Africa through detailed case studies of local governments in five countries.

This issue is also special because it brings together a unique set of African scholars who live under the region's decentralised systems (with the exception of Crook), and study them with a proximate lens often denied to visiting scholars from other, usually Northern countries. More importantly, these scholars regularly work together as a team to conduct annual trainings on research methods for university staff from across the African continent. This orientation is obvious in the design of each study, uniquely formulated to deal with research questions that are on the policy agenda in each country. The questions are all currently relevant - and so it is no surprise then that the topic chosen for investigation by each country team matches the issues highlighted by the IIAG 2016 - and they are held together by the common belief that more innovative methods should now be applied to these questions in order to achieve better and deeper explanations. The composition of the team and their approach to the subject brings a thematic and methodological freshness to this issue.

The two articles on Ghana look at public administration, fiscal transfers and local revenue mobilisation. In other words, they look specifically at the indicators on which Ghana has registered decreases over the past decade. Crook looks at the issue of local versus central funding of local government expenditures, and explores in particular whether democratic 
decentralisation means that Ghana's District Assemblies can raise more local revenues, and in the process engage more with citizens to deliver better services. His article deals centrally with the question of whether public administration and service delivery are negatively affected by the way in which democratic decentralisation interacts with the logic of a clientelist political system. Doh's article, on the other hand, looks at the extent to which staff quality within the local bureaucracy makes a difference to local service provision. In the context of plans for greater decentralisation in Ghana and giving District Assemblies more devolved responsibility for service delivery, Crook and Doh's articles draw our attention to the types of factors that can limit performance both within the system (through staff quality) and outside it (through clientelism).

The study on Kenya looks at citizen perception of maternal healthcare provision by local governments, and demonstrates how this is commensurate with the improvements in health care registered by the IIAG 2016. Kilonzo, Kamaara and Magak tell us, however, that there are differences in the perceptions of service users and service providers. Users are generally satisfied while providers, with a broader and more intimate view of the system, complain about the inadequacy of a number of facets, largely the result of limitations placed on local healthcare provision by higher tiers of government. The fact of perceptions being closely linked to sectional views of the system is an important one, especially when it applies to deepening ethnic discrimination in more heterogeneous counties (the unit of local government in Kenya).

This works the other way round in Nigeria in the context of high insecurity and citizens' growing concerns about their own safety. Here better services do not seem to be connected to better perceptions of provision by communities. In this case, the authors Ojebode, Onyishi and Aremu tell us that perceptions are closely related to expectations that are built through the practice of local democracy, in particular through campaign promises made in a context of very limited resources, an echo of the impact of clientelism in Ghana. Democratic decentralisation interacts with limited fiscal decentralisation and autonomy to lead to unfavourable perceptions by constituents, and a feeling of being let down yet again by politicians.

The Uganda study explores the conundrum of how some of the country's education indicators have improved over time (for instance, human resources in primary schools and government support for education), while completion rates remain stagnant (they actually decrease if we look at the trend over the past 15 years (Mo Ibrahim Foundation 2016b)). Maractho points out that part of the answer might lie in how government handles educational needs, with the liberalisation of education widening a gap between public and private education, and, once again, resource differentials affecting the quality of provision by local governments.

The Ethiopia article uses the case of waste management in the capital city of Addis Ababa to provide a quite unique perspective on why 
the country is not performing well on indicators for participation and human rights. Alemu examines the decline in the quality of waste collection and recycling services in the city by comparing the role of formal and informal actors, based on the premise that it is the increasing centralisation tendencies of the Ethiopian government that is leading to reduced participation by previously active actors within service delivery networks. The study alerts us to the fact that decentralisation reforms that formalise processes and procedures indiscriminately may lead to worse, rather than better, services.

What particular contributions does this issue make to the above debates over decentralisation and governance reform? First and foremost, it highlights an area where the literature continues to be very limited. By this, we do not refer simply to literature on decentralisation in Africa, but also to literature on this subject by African scholars, and to studies that are comparative and provide a systematic analysis of the outcomes of decentralisation efforts. In other words, this IDS Bulletin offers studies by African scholars that observe the functioning and impact of decentralisation at the most micro level through detailed cases that draw out nuanced differences between different parts of the country, different political systems, and different political actors. Besides this fundamental contribution, this IDS Bulletin also provides insights into three main issues within the study of decentralisation.

\subsection{An incomplete agenda}

Decentralisation reforms have been put forward as the answer to many of the governance problems of emerging democracies. As suggested earlier, the argument is that bringing decision-making closer to people provides greater opportunities for participation, more relevant policies, more rational expenditure, and so helps improve local governance. However, the literature also accepts that the decentralisation agenda remains incomplete in most countries. Sometimes this is because of the partial implementation of administrative, political and fiscal devolution, while at other times it is because of the absence of other complementary changes that are required to ensure that decentralisation efforts will succeed. This is the overall, collective story that the articles in this issue tell.

It is not a surprise that each study highlights a fairly similar set of missing elements. Almost everyone agrees that there is a lack of funds at the local level - in some cases central transfers do not adequately match local needs, or do not correspond to the functions legally devolved to local governments; in other cases, political manoeuvres and clientelistic politics lead to funds being distributed unevenly or ineffectively across districts; and in almost all cases, local authorities do not have the power to raise adequate local funds.

Another regularly cited issue is the continuing centralisation tendencies of higher tiers of government. The reluctance by African governments to decentralise power, noted by Conyers in the foreword of this issue and in her earlier articles $(1983,2007)$, remains true today. This is 
recent renewed commitments to decentralisation in some countries, such as in Ethiopia in 2005, and in Kenya in 2010. A number of papers point out that national and state governments' need to hold on to power leads to limited space available for lower tier governments within districts and counties to make substantive decisions that would lead to service delivery improvements within their areas.

The studies approach decentralisation by examining specific aspects of local administration and the delivery of specific services - local revenue mobilisation and the motivation of frontline workers for public service in the case of Ghana, security provision in the case of Nigeria, urban solid waste management in Ethiopia, maternal health care in Kenya, and primary education in Uganda. This case-based exploration leads them to identify the key factors that limit the quality and efficacy of delivery in each case. For instance, there is a need:

For central governments to provide more untied funds - and therefore more autonomy - to local governments (see the cases of Nigeria, Kenya and Uganda);

To provide incentives to attract better quality staff to far flung parts of each country, avoiding an internal 'brain drain' to better-off urban centres and nearby regions (see Ghana and Uganda);

To strengthen local accountability, ensuring greater fairness and equity in service delivery, reducing the impact of political patronage, as well as allowing more actors to participate in more democratically organised spaces (see Ghana, Nigeria, Kenya and Ethiopia).

Any one of these reforms may not in itself ensure better access to and quality of local services, but if decentralisation is to remain on the agenda, it cannot function within the strangleholds placed on it by limited funds, restricted autonomy, exclusive spaces and clientelistic politics. The lack of such complementary reforms only sets local governments up for failure, and risks fostering disillusionment with the system as a whole, as argued by several of the contributors.

\subsection{The need for multi-actor coalitions}

Effective service delivery at the local level usually involves coordinated multi-sectoral and multi-actor efforts. Together the articles in this issue tell us that when such broad cooperation is missing, the performance of local governments suffers. In fact, they make an interesting observation as a set: decentralisation does not mitigate against the centralising tendencies of different levels of government - state governments in Nigeria that maintain control over the disbursement of funds that come from the centre, as well as over the electoral process by appointing rather than electing many local governments; the city government of Addis Ababa that will not share responsibilities with other departments or with informal actors; and the concentration of development around headquarters of councils and counties, as in Uganda, Kenya and Ghana. In other words, decentralised government does not mean that 
power will be shared with local governments, or by local governments with other state departments and non-state actors, or by towns with more remote parts of the county or district.

Cooperation across formal actors requires that different state departments coordinate their efforts at the frontline. Coordination between formal and informal actors occurs when local governments open up more participatory decision-making spaces for actors who have no formal responsibility for service delivery, but play an active and significant role within it in any case. The impact of informal actors and institutions, however, can work in two very different ways.

On the one hand, their inclusion in local government processes can strengthen local democracy by allowing budgetary and distributive decisions to more closely reflect local needs, and for services to be delivered more cost-effectively through existing channels (Scheye 2009; Ananth Pur and Moore 2010; Mohmand and Mišić Mihajlović 2014). This is the view that both Alemu and Ojebode et al. take in the Ethiopia and Nigeria articles respectively.

Alemu's study of Addis Ababa's solid waste management system adequately demonstrates how service delivery suffers when state institutions that are given prime responsibility to deliver a service refuse to build broad-based coalitions with other state and non-state actors. In this case, those actors include the health department and a range of informal actors who facilitate the collection and recycling of waste in the city. Ojebode et al.'s article on security provision by local governments in Nigeria also demonstrates how, despite the fact that various non-state actors, such as community leaders and groups of local volunteers, play an important role in ensuring safe communities, their integration into formal processes is ad hoc and arbitrary.

On the other hand, the involvement of local non-state actors can strengthen clientelistic politics at the local level (Baldwin 2007; Gay 2009), limiting the fairness and equity of distribution as service delivery becomes a quid pro quo arrangement tied to votes. The local power and privilege of some non-state actors could also interact with greater resources at the local level in ways that skew distribution and lead to the capture of development funds and services (Bardhan and Mookherjee 2006a). This is the view that both Crook and Ojebode et al. take in their articles on Ghana and Nigeria.

Crook shows how, despite years of consolidated democratic local government in Ghana through its District Assemblies, neither local resource mobilisation nor developmental efforts have improved substantially, largely because of clientelistic politics that represent the interests of only sections of the population. Politicians at all levels, including at the local level, often provide services to constituents in return for votes, and not because they are the section of population that most require those services. This form of politics distorts theoretical 
linkages - such as 'principal-agent' models of political accountability between decentralisation reforms and outcomes. Ojebode et al. make a similar argument, and highlight in particular the ability of local political 'godfathers' in Nigeria to squeeze local government resources to the extent that they leave little room for effective delivery by councils.

The impact of a greater number of actors playing a role in local service delivery is also highlighted in some way by the other articles. The Uganda article by Maractho focuses on differences in the provision of primary education by local governments when donors and private actors get involved. Both these sets of non-state actors use selection criteria for provision that are not always obvious to other stakeholders, but their involvement in a given district can substantially improve its performance indicators. This makes the point that despite one of the most impressive decentralisation efforts in Africa and a programme fully focused on the improvement of delivery of primary education, Uganda's local governments are unable to deliver quality services, and the existence of 'islands of efficiency' appear to be a result of interventions by external actors. The Kenya article makes reference to the impact of more political actors at the local level. Here, as in other countries, the new tier of local government has introduced party competition at the local level, and a greater role for opposition parties. Decentralisation has, therefore, increased the number of political actors at the local level, made room for political coalitions, and in the process, given citizens a larger space for demanding services.

\subsection{Comparative analyses of decentralisation}

Ribot's (2002b) review of studies on decentralisation in Africa points out that a comparative lens is an under-utilised tool for examining local government reforms in the continent. This has not changed much in the decade and a half since then. There is a clear need to use more innovative methods and more incisive tools. Comparative analysis carried out at the most local level - within councils that can be studied either in comparison to one another, or then contrasted as two cases - can yield more grounded, empirical stories and narratives. However, the African research context is a difficult one. There are three constraints in particular: limited availability of existing data; difficulty of access to data that does exist because of bureaucratic processes, and concerns about quality and rigour (Smoke 2015). While these constraints call for the gathering of more primary evidence, resources for doing so are limited.

These are constraints that this team of researchers faced in good quantity, and so they set out to look for fresh evidence to the extent that the resources available to them could afford. Each of the articles in this issue makes a concerted effort to use a detailed, micro and comparative lens to the extent possible. In some cases, the teams persevered. In others, it became so difficult given the circumstances that they had to modify their strategy to a more modest objective. But the contribution to the understudied comparative field of decentralisation in Africa, and 
particularly of people's perception of what decentralisation means to them, is obvious in each case.

The Nigerian article compares citizens' perception of the efficacy of local councils that are elected with those that are appointed, in delivering security services, and finds that quite unexpectedly, citizens have a better impression of the work of unelected councils as compared to elected ones. Doh's study of Ghana does not directly compare the two districts in which it is based, but does examine how staff quality explains service delivery outcomes in two different District Assemblies - one that is at the top and the other at the bottom of the official District League Table - making an effort to draw out a detailed pathway to explain the different outcomes in each case. The Ugandan study compares two districts and their differential primary schooling outcomes to find that donor and private sector involvement provides positive distortions in the quality of primary education. In Kenya, Kilonzo and her co-authors consider the perceptions of citizens regarding improvements in access to health services in two different counties, comparing these largely positive perceptions to the less favourable ones of service providers themselves in both cases, a difference they suggest comes from improved access itself. As the number of users increases, while fiscal remittances from the national government do not, the local health-care system is put under ever increasing pressure. In the article on Ethiopia, the comparison is between the role of formal and informal actors in waste management.

The articles also use a variety of other tools to develop their arguments. Alemu uses social network analysis to compare the role of formal and informal actors in Addis Ababa. Kilonzo et al. make use of ethnographic methods to understand access to maternal health care in Kenya, while Maractho uses in-depth interviews with key actors. Both Doh and Ojebode et al. combine qualitative and quantitative tools to draw out causal mechanisms, or pathways, to explain how a set of initial conditions led to the observed outcomes in each case.

Each author is able to draw out a very particular perspective based on the method they use to investigate the question, and the choice of method is to a large extent based on the question itself. So, for example, ethnographic research is employed when the purpose is to probe complex and multidimensional processes; social network analysis is used when the purpose is to uncover actors and actions; and paired case and pathway analysis is used to explain how a particular outcome may have occurred. This is good practice, and recent calls for the use of more innovative and mixed methods, such as by Creswell and Plano Clark (2007), have argued that methods should be determined by the questions we ask and the contexts in which we apply them.

\section{A diverse yet unified approach}

This IDS Bulletin as a whole tests the relationship between decentralisation and a list of outcomes - from maternal health care and education, to solid waste management and crime prevention - using a mix of methods 
to answer questions about whether or not decentralisation can lead to better services in emerging economies. The contents of these pages should be of particular interest to scholars working on decentralisation in Africa, policymakers in African ministries, aid agencies, and civil society organisations working on the delivery of essential services in Africa. Each case study is led and researched by an in-country team of scholars, all of whom come from different disciplines and use different methods and approaches to the central question. This allows the issue to present a real diversity of viewpoints from across the African region - allowing us to hear more directly from African scholars who work and teach in its universities, in their voice and in their style.

At the same time, the work of these authors is held together by a commitment to more innovative and rigorous approaches to studying Africa's policy questions. The researchers that came together to produce this issue represent a group of scholars who work with the Partnership for African and Social Governance Research (PASGR) and IDS to train early and mid-career researchers in African universities in a variety of methods. They are alumni of the programme themselves, and are now its main instructors. This coalition of institutions and researchers represents important steps forward in the direction of strengthening research in Africa - introducing new methods, working with university bureaucracies to expand the available space for research, improving university-based teaching of methods, and raising funds for new research - but the challenges remain large.

Decentralisation is an important issue in Africa, but the challenges faced by university-based researchers in the region mean that systematic analyses of its outcomes are still limited. The studies in this IDS Bulletin represent first efforts by a set of scholars to use more innovative and incisive methods to understand decentralisation and its impact in Africa. With more resources and time, these lines of enquiry can be both strengthened and deepened to provide better explanations. The set of studies presented here already represent exciting and important new contributions to a field of study that requires more attention.

\section{References}

Ananth Pur, K. and Moore, M. (2010) 'Ambiguous Institutions: Traditional Governance and Local Democracy in Rural South India', Journal of Development Studies 46.4: 603-23

Baldwin, K. (2007) 'Bringing Traditional Patrons Back into the Study of Patronage: Chiefs and Politics in Zambia', paper presented at the American Sociological Conference 2007, New York, 18-21 October 2007

Bardhan, P. and Mookherjee, D. (2006a) 'Decentralisation and Accountability in Infrastructure Delivery in Developing Countries', Economic fournal 116: 101-27

Bardhan, P. and Mookherjee, D. (2006b) Decentralization and Local Governance in Developing Countries: A Comparative Perspective, Cambridge: MIT Press 
Bratton, M. (2012) 'Citizen Perceptions of Local Government Responsiveness in Sub-Saharan Africa', World Development 40.3: 516-27

Conyers, D. (2007) 'Decentralisation and Service Delivery: Lessons from Sub-Saharan Africa', IDS Bulletin 38.1: 18-32, http://bulletin.ids. ac.uk/idsbo/article/view/888 (accessed 13 February 2017)

Conyers, D. (1983) 'Decentralisation: The Latest Fashion in Development Administration?', Public Administration and Development 3.2: 97-109

Crawford, G. and Hartmann, C. (eds) (2008) Decentralisation in Africa: A Pathway out of Poverty?, Amsterdam: Amsterdam University Press

Creswell, J.W. and Plano Clark, V. L. (2007) Designing and Conducting Mixed Methods Research, Thousand Oaks CA: Sage

Crook, R. and Manor, J. (1998) Democracy and Decentralisation in South Asia and West Africa, Cambridge: Cambridge University Press

Faguet, Jean-Paul (2014) 'Decentralization and Governance', World Development 53: 2-13

Faguet, Jean-Paul (2012) Decentralization and Popular Democracy: Governance from Below in Bolivia, Ann Arbor MI: University of Michigan Press

Gay, R. (2009) 'Community Organization and Clientelist Politics in Contemporary Brazil: A Case Study from Suburban Rio de Janeiro', International fournal of Urban and Regional Research 14.4: 648-66

Heller, P. (2001) 'Moving the State: The Politics of Democratic Decentralization in Kerala, South Africa, and Porto Alegre', Politics and Society 29.1: 1-28

Joshi, A. and Schultze-Kraft, M. (2014) 'Introduction - Localising Governance: An Outlook on Research and Policy', IDS Bulletin 45.5: 1-8, http://bulletin.ids.ac.uk/idsbo/article/view/146 (accessed 13 February 2017)

Mo Ibrahim Foundation (2016a) A Decade of African Governance 20062015: 2016 Ibrahim Index of African Governance, London: Mo Ibrahim Foundation

Mo Ibrahim Foundation (2016b) Ibrahim Index of African Governance, data portal, http://iiag.online/ (accessed 3 February 2017)

Mohmand, S.K. and Mišić Mihajlović, S. (2014) 'Connecting Citizens to the State: Informal Local Governance Institutions in the Western Balkans', IDS Bulletin 45.5: 81-91, http://bulletin.ids.ac.uk/idsbo/ article/view/153 (accessed 13 February 2017)

Ribot, J.C. (2002a) Democratic Decentralization of Natural Resources: Institutionalizing Popular Participation, Washington DC: World Resources Institute

Ribot, J.C. (2002b) African Decentralization: Local Actors, Powers and Accountability, UNRISD Programme on Democracy, Governance and Human Rights, Paper 8, Geneva: UNRISD

Scheye, E. (2009) State-Provided Service, Contracting Out, And Non-State Networks: Fustice and Security as Public and Private Goods and Services, discussion paper commissioned by the International Network on Conflict and Fragility, Paris: OECD

Smoke, P. (2015) 'Rethinking Decentralization: Assessing Challenges to a Popular Public Sector Reform', Public Administration and Development 35.2: $97-112$ 
Treisman, D. (2007) The Architecture of Government: Rethinking Political Decentralization, Cambridge: Cambridge University Press

Wunsch, J. and Oluwu, D. (eds) (2003) Local Governance in Africa: The Challenges of Decentralization, Boulder CO: Lynne Rienner 